\title{
PREPARO DO PACIENTE PARA A ALTA HOSPITALAR - DESCRIÇão de UMA SITUAÇão
}

\author{
Djair Daniel Nakamae*
}

NARAMAE, D.D. - Preparo do paciente para a alta hospitalar - Descrição de uma situação. Rev. Bras. En?.; 19 : 36-39, 1976.

Adão O.M., 49 anos de idade, casado. pai de quatro filhos, vendedor ambulante, instrução primária, procedente do interior de São Paulo, é portador de Hipertensão arterial primária descoberta há dois anos, por ocasião de uma crise hipertensiva. $\mathrm{Na}$ oportunidade respondeu bem à terapeutica médica, mas por-não se ter tratado adequadamente, controlando a pressão arterial de maneira irregular, fol atendido no Pronto Socorro em outubro de 1975 devido a um surto de confusão mental. Constatou-se crise hipertensiva grave (PA 270/150 mmHg), com sério risco de acidente vascular cerebral. As exploraçōes diagnósticas mostraram hipertrofia cardiaca, edema cerebral e fundo de olho em grau III, o que motivou a internação do paciente na sala de diálise.

Recebendo tratamento hipotensor énergico, bem como diálise peritoneal para remoção de grande edema, após quatro dias seu estado mental praticamente se normalizou.

Submetido a numerosos exames, constatou-se que sua hipertensão era primá- ria ou essencial, isto é, de causa desconhecida, portanto sem tratamento etiológico e tāo somente paliativo. Isso equivale a dizer que dependerá de medicação hipotensora e controle médico periódico pelo resto da vida.

Uma vez normalizada a pressão arterial e removidos os edemas, o paciente vencia mais um estado crítico da sua doença.

Transferido para um leito da ala, comunicativo, demonstrava já se ter adaptado às rotinas do hospital, pois aceita. va tudo de boa vontade. Com regularidade recebia visitas da esposa e dos filhos. A filha mais velha é casada, duas outras são maiores, solteiras, e trabalham no comércio em sua cidade. Os dois filhos menores trabalham e cursam o ginásio.

Conversando com o paciente sobre seu estado de saúde, mostrou-se esperançoso com a alta. Disse ter-se curado e acrescentou, com ênfase, que sempre foi "muito forte, sadio e trabalhador, sendo muito estimado pela familia".

- Auxdliar de Ensino do Departamento de Enfermagem Médico-Cirúrgica da Escola de Enfermagem da UBP. 
NAKAMAE, D.D. - Preparo do paciente para a alta hospitalar - Descriçāo de uma situaçāo. Rev. Bras. Enf.; 19 : 36-39, 1976.

- Sr. Adão, sabe direitinho tudo o que ocorreu com o senhor?

- a pressão do sangue que ficou alta, mas já estou bem agora.

Explorou-se um pouco mais sobre o que queria dizer com 'pressão do sangue está muito alta". Verificou-se que era tão somente isso que sabia, desconhecendo causas, efeitos e conseqüências do mal. Sabia apenas que ela "subiu, desceu e estava curado agora".

O Sr. Adão, ao que parece, demonstrou não estar preparado para assumir a responsabilidade de seu tratamento. A convicção de estar curado e a ignorância das conseqüências de sua doença, provavelmente, o levarão ao ponto em que estava, se não se fizer algo para informá-lo melhor. Seu prognóstico só é bom se se mantiver normotenso, através da observância da terapêutica médica do autocuidado e do controle médico periódico.

\section{PROBLEMA E CONDIÇÓES}

Os comportamentos expressos pelo paciente durante a internação permitem prever como reagirá ao reassumir seu papel na sociedade. $O$ problema da situação consiste em esclarecer como a enfermeira pode, efetivamente, atuar sobre o comportamento do paciente, em termos de planejamento futuro, para que ele em definitivo aprenda a viver satisfatoriamente com a sua doença. $O$ caminho mais indicado parece ser aquele que visa a dar ênfase aos comportamentos desejados e extinguir os inadequados.

Assim, de acordo com esses objetivos, os diferentes tipos de comportamento podem ser agrupados como segue:

- Compotamentos já existentes a serem aprimorados:

$\star$ Não se tratava adequadamente;

$\star$ Percepção incompleta e incorreta de sua doença;

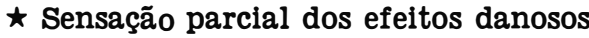

da mesma, dada a ignorância da relação de causa-efeito.

- Comportamento já existente a ser extinto:

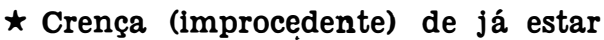
curado.

- Comportamentos já existentes a serem reforçados:

$\star$ Boa aceitação da medicação, da dieta e dos controles da enfermagem no hospital.

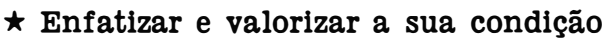
de: "ser forte" "ter tido sempre boa saúde", "ser trabalhador", "ser querido pelos seus familiares".

Do ponto de vista clínico, como se sabe, os seguintes aspectos são essenciais para a manutenção da saúde e prevenção de complicaçōes em pacientes portadores de hipertensão arterial:

* A rigor, a hipertensão arterial não é doença, quando se mantém compensada.

* A medicação hipotensora e diurética, associada a uma dieta com restrição de sal e a uma vida, tanto quanto possível, sem tensōes e esforços excessivos, é fundamental para essa compensação.

$\star$ O controle médico periódico para a avaliação e reajuste da terapêutica é igualmente indispensável.

\section{ORIENTAÇAO PARA A ALTA}

A interação enfermeira-paciente, quando efetiva, contribui para o aprendizado, aquisição e modificação do comportamento deste último. Todavia, seu efeito será mais eficaz e facilitado quando dispōe do reforço de outros elementos da equipe. Na situação em estudo, obteve-se a colaboração do médico, da nutricionista e dos familiares do paciente.

importante lembrar que em qualquer momento o paciente precisa sentir-se aceito pela enfermeira e tal só ocorrerá quando ela demonstrar essa aceitação através de sua atitude de interesse pelo que ele tem a dizer, expressando preo- 
NARAMAE, D.D. - Preparo do paciente para a alta hospitalar - Descrição de uma situação. Rev. Bras. Ene.; 19 : 36-3S, 1976.

cupação pelo seu bem-estar, a fim de que esteja físicamente cômodo, etc.

A seguir pōe-se em destaque os pontos que devem ser tratados.

Orientação sobre a doença, suas complicaçōes e a terapêutica. Tendo em vista que todo individuo tem necessidade de perceber claramente a situação pessoal, a intenção é corrigir um conhecimento débil, a fím de tornar mais estável sua atitude e mais positiva sua conduta. Nessa orientação parte-se das noçōes que ele já possui e tenta-se explicar porque isso ocorre, de modo simples e exato, à altura da compreensão do paciente, e dizendo sempre a verdade. $\mathrm{t}$ preciso "cobrar' para verificar o que foi retido. Deve-se ensinar novamente. Há necessidade de convencê-lo a agir bem e a cooperar expontaneamente com a equipe de saúde em seu próprio benefício. $E$, pois, importante ajudá-lo a enfrentar a realidade com firmeza e apoio ("o senhor val conseguir, será capaz...").

$\star$ Reforço do valor que o paciente atribui ao fato de ser forte e sadio. Conhecendo sua doença, ser-lhe-á mais fácil cooperar no tratamento e conseqüentemente se manterá sadio (normotenso), evitando as lesōes da moléstia a longo prazo.

* Apelar para sua conduta positiva, na enfermaria, de modo a aceitar bem o tratamento.

* Instrução minuciosa sobre os medicamentos, sua posologia e os efeitos esperados, motivando o paciente para um longo processo de tratamento.

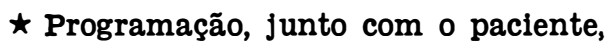
dos horários mais convenientes para tomar a medicação sem risco de esquecimento, do dia da semana mais propício para ir à farmácia controlar o peso e a pressão. Orientá-lo na manutenção do registro desses dados adequadamente. Fazer ver ao paciente que quando observa variaçōes significativas deve procurar assistência médica mesmo fora do dia da consulta. Ele precisa saber avaliar o perigo de estar descontrolada sua PA e cientificar-se da importância de sua cooperação no retorno periódico ao ambulatório para conseguir um ótimo controle.

* Com a nutricionista orientação da esposa (ou filha) sobre como preparar a dieta com restrição de sal, mediante o fornecimento de receitas de picles e vinagrete próprios, a flm de melhorar o sabor das refeiçōes.

* Enfase ao fato de 0 paciente ser querido pelos seus familiares e à importância da manutenção dessa atmosfera sem tensōes. Explicar-lhe que o fato de ser trabalhador lhe dá direito ao sono e repouso suficientes, a férias e fins-desemana recreativos. Realçar que para todo indivíduo que deseja manter-se sadio tais hábitos são altamente valiosos.

Vale salientar que no caso em análise essas orientaçōes foram dosadas durante contatos periódicos (três vezes por semana, durante catorze dias). Houve preocupação de em nenhum momento tocar em pontos negativos, do tipo "o Sr. acha que já está curado", "não se tratava adequadamente antes", "nada sabe sobre sua doença". Enquanto isso, os pontos positivos foram devidamente destacados em todos os contatos: "o sr. é forte", "é trabalhador", "é sadio desde que mantenha a pressão compensada". A palavra "doença" foi sistematicamente evitada. Por outro lado o termo "sadio" fol sempre associado a pressão compensada, e esta acompanhada das noçōes de "tomar medicamentos", "aceitar a dieta e manter controle médico". Com isso viscu-se não reforçar o comportamento indesejado (negativo), mas sim reforçar positivamente aqueles que necessitam ser desenvolvidos ou adquiridos.

Manteve-se o médico a par da conduta do paciente e o modo como seria manipulado, pedindo-lhe que em seus contatos salientasse os pontos positivos. Essa cooperação mostrou-se bastante valiosa. 
NAKAMAE, D.D. - Preparo do paciente para a alta hospitalar - Descriçāo de uma situaçäo. Rev. Bras. En?.; 19 : 36-39, 1976.

Mantiveram-se vários contatos com a filha e a esposa, as quais receberam a mesma orientação, com ênfase especial para os riscos decorrentes da falta de controle, pedindo-lhes que reforçassem sempre os pontos positivos e fornecessem ambiente adequado.

A nutricionista, bem a par da situação, também colaborou, elogiando a boa vontade do paciente, sua inteligência e capacidade de cooperar.

\section{RESULTADOS E EXPECTATIVAS}

Até o momento o paciente não teve alta. Contudo, parece seguro de si e demonstra calma e tranquilidade quanto à evolução da doença. Fol possível sentir que o paciente evoluiu no aprendizado, que os pontos básicos foram assimilados, uma vez que demonstrou saber usá-los quando submetido a testes.

Não se pode garantir ainda se seu comportamento fol modelado. Apenas foram oferecidas ao paciente as condiçōes que podem tornar mais freqüentes os comportamentos desejados.

A atuação efetiva da enfermeira, parece, consistiu em fazê-lo perceber melhor a situação que ignorava, sem todavia amedrontá-lo; usar suas percepçōes valorativas em benefício de uma conduta positiva em relação ao controle e tratamento da doença. Fol dada ênfase às conseqüências imediatas positivos: ter saúde, manter-se forte, sem ameaças futuras.

Em suma, a situação descrita mostra um processo de manipulação de comportamento, a fim de readaptar o paciente, para assumir no seu meio social um papel parcialmente modificado pela doença.

Viu-se que ele reagiu com descuido a uma doença que pôs em risco sua vida, por ignorar o mecanismo e conseqüências daquela, bem como o valor da terapêutica e do controle médico. $O$ paciente detinha a crença de ser forte e sadio com seus valores implícitos e simultaneamente a consciência de sua condição de hipertenso, necessitado de controle médico e de medicamentos, certamente dava origem a conflitos, debatendo-se ante uma auto-imagem que talvez julgasse negativa. Assim, o processo adotado consistiu em mostrar-lhe que continuará a ser forte e sadio desde que aceite fazer um tratamento e um controle, os quais, agora bem compreendidos, nada lhe custam e preservarão a imagem que sempre teve de sí.

\section{BIBLIOGRAFIA CONSULTADA}

MANN, L. - Actitudes - in Elementos de Psicologia Social, Editorial Linusa Wiley, S.A., México, 1972. 